Loghat Arabi: Jurnal Bahasa Arab dan Pendidikan Bahasa Arab

P-ISSN: 2722-1180 | E-ISSN: 2722-1199

Vol. 2, No. 1, Juni 2021

\title{
Efekivitas Penerapan Metode Hiwar Untuk Meningkatkan Keterampilan Berbicara Siswa Kelas VIII MTs Hikmat Tuttula Kecamatan Tapango Kabupaten Polewali Mandar
}

\author{
Hasria $^{1}$, Mujahid ${ }^{2}$, Rahmat $R^{3}$ \\ ${ }^{1,2,3}$ Institut Agama Islam DDI Polewali Mandar, Sulawesi Barat \\ 1e-mail: hasriaidris@gmail.com \\ e-mail: mujahid@ddipolman.ac.id \\ 3e-mail: rahmat@ddipolman.ac.id
}

\begin{abstract}
Abstrak
Penelitian ini mengkaji tentang efektivitas penerapan metode hiwar untuk meningkatka keterampilan berbicara (maharah kalam) siswa kelas VIII MTs Hikmat Tuttula Kecamatan Tapango Kabupaten Polewali Mandar. Jenis penelitian yang digunakan adalah penilitian kuantitatif yang bertujuan untuk memberikan informasi secara tepat dan jelas tentang penerapan metode hiwar dalam pembelajaran bahasa Arab di kelas VIII MTs Hikmat Tuttula. Pengumpulan datanya bersumber dari guru, siswa, maupun sarana pembelajaran lainnya berupa media dan dokumen. Adapun metode penumpulan datanya adalah lewat observasi, butir test dan dokumentasi. Penelitian ini menggunakan analisis deskriptif. Hasil penelitian ini menunjukkan bahwa kemampuan berbicara bahasa Arab (maharah kalam) siswa kelas VIII Hikmat Tuttula sebelum penerapan metode hiwar masih sangat kurang. Adapun setelah penerapan metode hiwar, kemampuan maharah kalam siwa kelas VIII MTs Hikmat Tuttula mencapai kriteria ketuntasan minimum (KKM). Sehingga dapat dikatakan bahwa penerapan metode hiwar efektif untuk meningkatan maharah kalam siswa kelas VIII MTs Hikmat Tuttula Kecamatan Tapango Kabupaten Polewali Mandar.
\end{abstract}

Kata Kunci: Metode Hiwar, Maharah Kalam, Bahasa Arab

\begin{abstract}
This study discusses the effectiveness of the application of the hiwar method to improve the speaking skills (maharah kalam) of class VIII students of MTs Hikmat Tuttula, Tapango District, Polewali Mandar Regency. The type of research used is quantitative research that aims to provide precise and clear information about the application of the hiwar method in learning Arabic in class VIII MTs Hikmat Tuttula. The data collection is sourced from teachers, students, and other learning facilities in the form of media and documents. The data collection method is through observation, test items and documentation. This research uses quantitative descriptive analysis. The results of this study indicate that the ability to speak Arabic (maharah kalam) of class VIII students of Hikmat Tuttula before the application of the hiwar method is still very lacking. Meanwhile, after the application of the hiwar method, the ability of maharah kalam students of class VIII MTs Hikmat Tuttula reached the minimum completeness criteria (KKM). So it can be said that the application of the hiwar method is effective for increasing maharah kalam for class VIII students of MTs Hikmat Tuttula, Tapango District, Polewali Mandar Regency.
\end{abstract}

Keywords: Hiwar Method, The Speaking Skills, Arabic Language

https://journal.iaiddipolman.ac.id/index.php/loghat/index 


\section{Loghat Arabi: Jurnal Bahasa Arab dan Pendidikan Bahasa Arab}

P-ISSN: 2722-1180 | E-ISSN: 2722-1199

Vol. 2, No. 1, Juni 2021

\section{Pendahuluan}

Bahasa Arab merupakan salah satu diantara mata pelajaran wajib yang dipelajari di sekolah agama tingkah menegah pertama (Madrasah Tsanawiyah). Mata pelajaran ini menjadi ciri khas tersendiri di lembaga keagamaan baik yang bersifat madrasah maupun mahad. Adapun kompetensi lulusan bahasa Arab yang diharapkan sebagaimana tertuang dalam Keputusan Menteri Agama Nomor: 165 Tahun 2014 ada 4 hal, yaitu kemampuan dari segi maharah alistima' (keterampilan menyimak), maharah al-kalam (kemampuan berbicara), maharah alqira'ah (kemampuan membaca), dan maharah al-kitabah (kemampuan menulis). ${ }^{1}$

Adapun klasifikasi persentasi empat keterampilan dalam pembelajaran bahasa Arab tingkat menengah adalah keterampilan menyimak (istima') sebanyak 35\%, keterampilan berbicara (al-tahadduts/al-kalam) sebanyak 35\%, keterampilan membaca (al-qira'ah) sebanyak $15 \%$ dan keterampilan menulis (al-kitabah) sebanyak 15\%. Adapaun jumlah kosakata yang direkomendasikan sebanyak 1000 sampai 1500 kosakata. $^{2}$

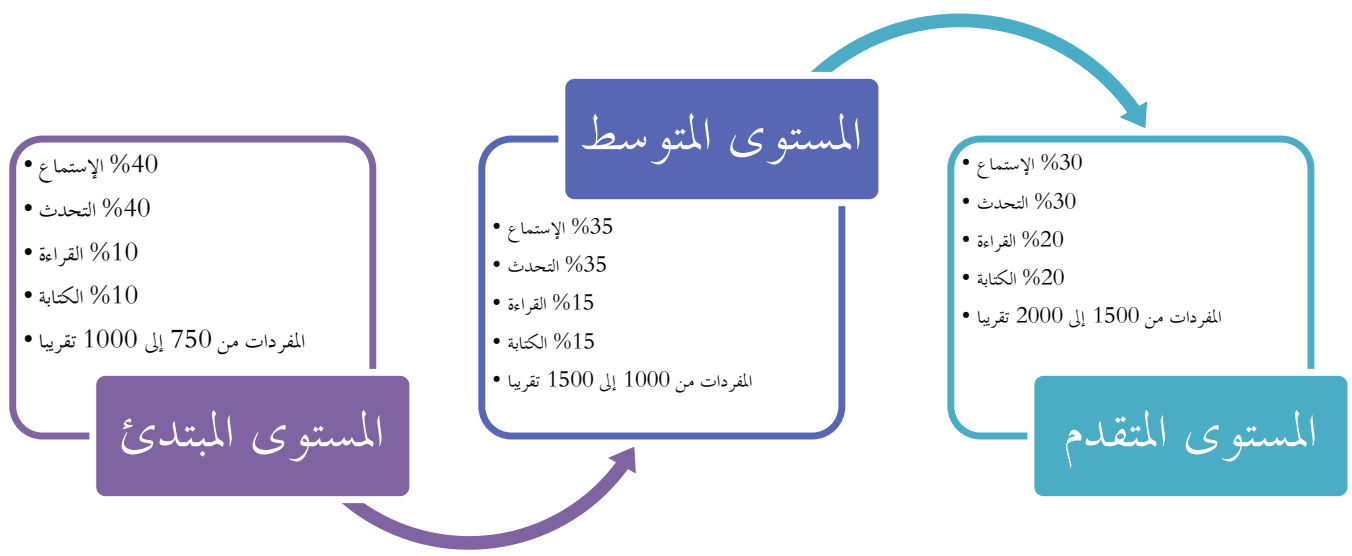

Tabel 1. Persentasi Distribusi Keterampilan Berbahasa secara umum ${ }^{3}$

Di samping kompetensi lulusan tersebut di atas, M. Abdul Hamid dkk. mengungkapkan bahwa pembelajaran bahasa Arab juga memiliki tujuan yang lain agar para peserta didik

\footnotetext{
${ }^{1}$ Peraturan Pemerintah RI Nomor 19 tahun 2005 tentang Standar Nasional Pendidikan. Lihat juga Ahmad Fuad Mahmud Aliyan, al-Maharat al-Lughawiyyah: Mahiyatuha wa TharaiqTadrisiha, (Riyadh: Dar al-Muslim lin Nasyr wat Tauzi', 1992), h. 43-44.

${ }^{2}$ Basri Mahmud, Hamzah. Pembelajaran Efektif dalam Pengajaran Bahasa Arab Tingkat Menengah, dalam Loghat Arabi: Jurnal Bahasa Arab dan Pendidikan Bahasa Arab, 1(1) 2020, h. 23-36.

${ }^{3}$ Mahmud 'Ali Syarabiy, Dalil Muta'allimiy al-'Arabiyyah lin Nathiqiyna bi Ghayriha, (Riyadh: Dar Wojooh lin Nasyir wat Tauzi', 2015)., h. 26.
} 


\section{Loghat Arabi: Jurnal Bahasa Arab dan Pendidikan Bahasa Arab}

berkembang dalam hal; pengetahuan mengenai ragam bahasa bahasa dan konteksnya, pengetahuan mengenai pola-pola kalimat, pengetahuan mengenai sejumlah teks yang beraneka ragam, kemampuan berbicara secara efektif dalam berbagai konteks, kemampuan menafsirkan isi berbagai bentuk teks tulis dan merespon dalam bentuk kegiatan yang beragam, kemampuan membaca buku bacaan fiksi dan non fiksi sederhana, kemampuan menulis kreatif berbagai bentuk teks, kemampuan menghayati dan meghargai karya orang lain dan kemampuan untuk berdiskusi dan menganalisis teks. ${ }^{4}$

Kemahiran berbahasa Arab adalah merupakan salah satu jenis kemampuan yang ingin dicapai dalam pengajaran bahasa Arab, karena bahasa Arab merupakan sarana utama untuk berkomunikasi dengan orang Arab dan memahami buku, sejarah, budaya atau kitab-kitab yang berbahasa Arab. Maka diperlukan pengoptimalan belajar dan mengajar bahasa Arab di dalam instansi pendidikan baik formal maupun non formal. Untuk itu, upaya-upaya pengoptimalan kegiatan belajar mengajar sangat tepat dilakukan demi meningkatkan kualitas pembelajaran bahasa Arab.

Pembelajaran bahasa Arab merupakan transformasi ilmu, sikap mental dan perilaku kebahasaan Arab yang diharapkan dapat dilakukan secara profesional dan beriorentasi kepada tujuan tertentu. Tujuan bahasa Arab dapat direalisasikan secara efektif jika dilandasi oleh visi, misi dan orientasi yang jelas terhadap prosedur yang dilakukan berlandaskan strategi, pendekatan dan metode yang tepat dan relevan sehingga mengasilkan out put yang optimal dan memuaskan, baik bagi peserta didik, guru maupun lembaga pendidikan dan masyarakat luas. ${ }^{5}$

Dalam pembelajaran bahasa Arab, terdapat 4 (empat) keterampilan dasar yang harus disukseskan untuk bisa dikuasai sebagai keterampilan dan kemampuan dasar siswa, yaitu keterampilan menyimak (maharah al-istima'), keterampilan berbicara atau bercakap (maharah al-kalam), keterampilan membaca (maharah al-qira'ah), dan keterampila menulis (maharah alkitabah). ${ }^{6}$ Untuk meningkatkan keterampilan-keterampilan tersebut, maka pendidik atau guru

\footnotetext{
${ }^{4}$ M. Abdul Hamid, dkk., Pembelajaran Bahasa Arab: Pendekatan, Metode, Startegi, Materi dan Media, (Cet. I; Malang: UIN-Malang Press, 2008), h. 159-160.

${ }^{5}$ Pambudi, Khafid. Pengaruh Pelaksanaan Praktek Muhadhasah Pagi terhadap Prestasi Belajar PAI (Materi alQur'an Hadits) Siswa di SMP Plus ar-Rahmat Bojonegoro. Diss. UIN Sunan Ampel Surabaya, 2014. http://digilib.uinsby.ac.id/820/

${ }^{6}$ Mahmud, Basri, and Hamzah Hamzah. "Pembelajaran Efektif dalam Pengajaran Bahasa Arab Tingkat Menengah." Loghat Arabi: Jurnal Bahasa Arab dan Pendidikan Bahasa Arab 1.1 (2020): 23-36.
} 


\section{Loghat Arabi: Jurnal Bahasa Arab dan Pendidikan Bahasa Arab}

bahasa Arab tentu harus memiliki kemampuan untuk melaksanakan proses pembelajaran dengan baik agar tujuan pembelajaran yang diinginkan dapat tercapai.

Realitas hari ini adalah dari keempat keterampilan tersebut, yang hanya dominan berkembang dan diasah oleh guru bahasa Arab adalah pada keterampilan reseptif (membaca dan menulis) saja dibandingkan dengan keterampilan aktif (mendengar dan berbicara). Dari keempat keterampilan tersebut, yang menjadi permasalahan utama adalah lemahnya siswa terhadap keterampilan berbicara (maharah kalam). Banyak siswa yang mengalami kesulitan berbicara baik dalam situasi non formal maupun formal. Saat berbicara di depan kelas misalnya, siswa terlihat gugup, pelafalan tidak jelas, intonasi monoton, dan bahasa kurang komunikatif. Hal-hal seperti itulah yang menjadikan rendahnya keterampilan berbicara siswa.

Maharah kalam merupakan suatu keterampilan menyampaikan pesan secara lisan kepada orang lain. Maharah kalam merupakan suatu keterampilan yang paling penting dalam berbahasa. Sebab berbicara adalah bagian dari keterampilan yang dipelajari oleh pengajar, sehingga keterampilan berbicara dianggap sebagai bagian yang sangat mendasar dalam mempelajari bahasa Asing. Dalam memulai latihan berbicara, terlebih dahulu harus didasari oleh kemampuan mendengar, kemampuan penguasaan kosa kata (mufradat) dan keberanian mengungkapkan apa yang ada dalam pikirannya. ${ }^{7}$

Bahasa Arab di Madrasah dipersiapkan untuk pencapaian kompetensi dasar berbahasa yang mencakup empat keterampilan berbahasa yang dilakukan secara integral. Namun saat proses pembelajaran bahasa Arab, ketika para siswa memasuki kelas mereka memiliki pengetahuan, kemampuan dan motivasi yang sangat beragam. Apabila guru masih menggunakan cara pembelajaran yang klasik maka akan tercipta pembelajaran satu arah dari guru ke siswa, hal ini akan membuat pembelajaran bersifat monoton dan kurang efektif. Terlebih lagi materi bahasa Arab didominasi dengan tampilan peranan guru yang cenderung hanya menjelaskan dan pembelajaran yang berpusat pada buku panduan bahasa Arab. Hal ini mengakibatkan siswa merasa jenuh dan menganggap materi tersebut tidak menarik.

\footnotetext{
${ }^{7}$ Mahmud Ali Muhammad Syarabiy, Istratiyjiyyah Muqtarahah Qaimah 'ala Madkhal al-Taqabuli al-Lughawiy wa Thalil al-Akhtha' fi Tanmiyah Maharat al-Fahmi al-Istima'iy wal Qira'ah al-jahriyyah wal Kitabah alWadhzifiyah laday Darisiy al-Lughah al- 'Arabiyyah al-Natiqinan bi Ghairiha, Risalah Dukturah. (Ma'had al-Dirasat al-Tarbawiyyah, Jami'ah al-Qahirah, 2011)., h. 179.
} 


\section{Loghat Arabi: Jurnal Bahasa Arab dan Pendidikan Bahasa Arab}

P-ISSN: 2722-1180 | E-ISSN: 2722-1199

Vol. 2, No. 1, Juni 2021

Atas dasar tersebut, maka seorang guru perlu menerapkan sebuah metode pembelajaran yang mampu menciptakan proses pembelajaran yang efektif. Dengan menggunakan metode pembelajaran yang sesuai dengan mata pelajaran bahasa Arab, hal ini dapat meningkatkan hasil belajar siswa. Dengan adanya metode belajar yang efektif, siswa akan lebih tertarik dalam mengikuti pembelajaran. Salah satu metode yang ingin diuji keefektifannya terhadap hasil belajar dan tingkat keterampilan maharah kalam siswa pada mata pelajaran bahasa Arab adalah metode hiwar.

Metode Hiwar merupakan metode percakapan atau dialog yang diajarkan perdialog oleh guru dengan bacaan yang jelas dan diikuti siswa secara kelompok baru dilakukan dengan meniru secara individu. Metode Hiwar bertujuan untuk melatih lidah atau ucapan siswa agar terbiasa dan fasih berbicara bahasa Arab. ${ }^{8}$ Metode Hiwar dapat menggugah kreativitas siswa, sebab dapat merangasang ide-ide kreatif yang dapat tumbuh seiring dengan motivasi yang berkembang dalam diri siswa. ${ }^{9}$

Faktor terpenting dalam menghidupkan kegiatan hiwar (berdialog) adalah keberanian peserta didik dan tidak takut salah. Oleh karena itu guru harus dapat memberikan motivasi kepada siswa agar mereka berani melakukan hiwar (dialog) meskipun salah. Dan hendaknya para siswa diberi wejangan bahwa takut salah dalam belajar bahasa Arab adalah suatu kesalahan besar. Sebab takut salah dan malu adalah hambatan untuk bisa terampil berbahasa Arab.

\section{Metode Penelitian}

Jenis penelitian yang digunakan adalah penilitian kuantitatif yang bertujuan untuk memberikan informasi secara tepat dan jelas tentang penerapan metode hiwar dalam pembelajaran bahasa Arab di kelas VIII MTs Hikmat Tuttula. Data-data dalam penilitian ini bersumber dari guru, siswa, maupun sarana pembelajaran lainnya berupa media dan dokmentasi. Adapun metode penumpulan data yang digunakan adalah melalui observasi, butir tes dan dokumentasi. Analisis data yang digunakan dalam penelitian ini menggunakan analisis statistik yang diajabarkan secara deskriptif.

\footnotetext{
${ }^{8}$ Imam Kurniawan, Anung Al Hamat, and Abdul Hayyi Al Kattani. "Metode Pembelajaran Kreatif Mata Pelajaran Bahasa Arab Untuk Kelas 1 Sekolah Dasar Islam.” Idarah Tarbawiyah: Journal of Management in Islamic Education 2.1 (2021): 13-20. https://doi.org/10.32832/itjmie.v2i1.3426

9 Muhammad Zakir. "Metode Mengajar dalam Pendidikan Islam (Kjian Tafsir Tarbawi)." Serambi tarbawi 4.2 (2016): 101-118. https://doi.org/10.32672/tarbawi.v4i2.1267
} 


\section{Loghat Arabi: Jurnal Bahasa Arab dan Pendidikan Bahasa Arab}

P-ISSN: 2722-1180 | E-ISSN: 2722-1199

Vol. 2, No. 1, Juni 2021

\section{Hasil Penelitian dan Pembahasan}

\section{Maharah kalam Siswa kelas VIII MTs Hikmat Tuttula Sebelum Penerapan Metode Hiwar}

Tingkat maharah kalam siswa sebelum penerapan metode hiwar, dikatakan masih rendah dan belum mencapai kriteria ketuntasan minimum (KKM) yaitu nilai 68. Hal ini diketahui dari jumlah 20 siswa yang tuntas belajar baru 7 anak atau 35\% siswa dan sisanya sisanya 13 anak atau $65 \%$ siswa belum tuntas. Lebih jelasnya dapat dilihat pada tabel berikut:

\begin{tabular}{|c|l|c|c|c|}
\hline No & Nama siswa & Nilai & Tuntas & $\begin{array}{c}\text { Tidak } \\
\text { Tuntas }\end{array}$ \\
\hline 1. & S1 & 51 & & $\sqrt{ }$ \\
\hline 2. & S2 & 51 & & $\sqrt{ }$ \\
\hline 3. & S3 & 61 & & $\sqrt{ }$ \\
\hline 4. & S4 & 77 & $\sqrt{ }$ & \multicolumn{2}{|c|}{} \\
\hline 5. & S5 & 64 & & $\sqrt{ }$ \\
\hline 6. & S6 & 51 & & $\sqrt{ }$ \\
\hline 7. & S7 & 83 & $\sqrt{ }$ & \\
\hline 8. & S8 & 77 & $\sqrt{ }$ & \\
\hline 9. & S9 & 77 & $\sqrt{ }$ & $\sqrt{ }$ \\
\hline 10. & S10 & 51 & & $\sqrt{ }$ \\
\hline 11. & S11 & 80 & $\sqrt{ }$ & $\sqrt{ }$ \\
\hline 12. & S12 & 61 & & $\sqrt{ }$ \\
\hline 13. & S13 & 61 & & $\sqrt{ }$ \\
\hline 14. & S14 & 51 & & $\sqrt{ }$ \\
\hline 15. & S15 & 61 & & $\sqrt{ }$ \\
\hline 16. & S16 & 51 & & \\
\hline 17. & S17 & 51 & & \\
\hline 18. & S18 & 80 & $\sqrt{ }$ & \\
\hline 19. & S19 & 64 & & \\
\hline 20. & S20 & & & \\
\hline
\end{tabular}

Tabel 2. Hasil test sebelum (pretest) penerapan metode hiwar

Data di atas menunjukkan bahwa kemampuan siswa dalam melaksanakan maharah kalam (bercakap Bahasa Arab) para siswa kelas VIII Hikmat Tuttula masih sangat kurang. Data ini berdasar pada strandar kelulusan minimum pada mata pelajaran Bahasa arab yaitu nilai 68 sedangkan data hasil belajar Bahasa arab pada kemampuan maharah kalam siswa pada saat kami berikan pretest hanya 7 orang saja yang melulusi standar kelulusan minimum. 


\section{Loghat Arabi: Jurnal Bahasa Arab dan Pendidikan Bahasa Arab}

\section{Maharah Kalam Siswa Kelas VIII Mts Hikmat Tuttula Setelah Penerapan Metode Hiwar}

Untuk mendapatkan keterampilan maharah kalam pada penelitian ini, juga terlebih dahulu diadakan pembelajaran yang metodenya menggunakan metode hiwar, adapun langkahlangkah pembelajaran yang dilakukan, pada pertemuan pertama dilaksanakan perkenalan antara peneliti dan siswa kemudian diberikan pretest selama 2 jam pelajaran (90 menit), perkenalan yang dilakukan lebih menyenangkan karena peneliti meminta para siswa menjelaskan namanya dengan menyebutkan terjemahannya saja dalam bahasa Indonesia karena secara kebetulan namanama peserta didik pada kelas tersebut kebanyakan dari bahasa Arab sehingga siswa terlihat sangat antusias untuk mencari terjemahan nama mereka karena bagi yang namanya dapat ditebak oleh peneliti mendapatkan hadiah permen, dan bagi siswa yang namanya berasal dari Bahasa Indonesia cukup mencari orang terkenal yang namanya sama lalu kemudian menceritakan karakternya. Pertemuan ini berlangsung sangat riang meskipun harus diakhiri dengan segera karena dilanjutkan dengan mengerjakan soal pretest pada pukul 09.00-10.00 hari sabtu, 26 September 2020.

Pada pertemuan ke-2 yaitu pada tanggal 03 Oktober 2020 jam ke 2 (09.00-10.00) dilaksanakan pembelajaran dengan materi الساعة dengan kemampuan istima'. Berdasarkan hasil ceklis pedoman observasi yang digunakan oleh peneliti. Pembelajaran pada kelas ini diawali dengan siswa merapikan tas dan mengatur jarak antara siswa sesuai dengan protokol kesehatan covid-19 yang dilaksanakan pada hari itu. Setelah itu, guru memberikan motivasi kepada siswa tentang hebatnya orang-orang yang cerdas berbahasa arab, dalam hal ini guru menjelaskan tentang kesuksesan seseorang yang memang menggeluti dunia bahasa arab yang mereka kenal sebagai orang yang hebat di sekolah mereka dengan sesekali meneriakkan kata-kata motivasi dalam bahasa arab (Man Jadda Wajada).

Dalam proses belajar terlebih dahulu guru atau peneliti meminta peserta didik membayangkan judul materi ajar sesuai dengan kehidupannya agar mereka lebih mudah memahami Materi yang diberikan, pada pertemuan pertama yaitu materi الساعة untuk menguasai Maharah kalam. Siswa diminta membayangkan tentang jam dan menyebutkan kosa kata apa yang mereka ingat. Langkah ini sangat membantu siswa mempercepat daya serap pemahaman karena mengaitkan dengan kehidupan sehari-hari, sebagaiman yang terdapat dalam konsep Hiwar. Pertama-tama guru membacakan mufradat berkaitan dengan materi hiwar kemudian 


\section{Loghat Arabi: Jurnal Bahasa Arab dan Pendidikan Bahasa Arab}

diikuti oleh siswa. Setelah siswa sudah lancar dalam menyebutkan mufradat dan memahami artinya. Perlahan guru meminta siswa mengamati tanpa suara selama 10 menit (baca dalam hati). Setelah itu, semua siswa diajak untuk mendengarkan baik-baik bacaan yang akan dibacakan dalam vidio setelah. Pemutaran dilakukan sebanyak 3 kali siswa diberikan kembali kertas yang sudah dikosongkan, sebagian kosa katanya untuk diisi sebagai penguatan pendengaran mereka sambil mendengarkan kembali rekaman sebelumnya.

Setelah pertemuan pertama dilakukan, interaksi guru dan siswa tidak hanya berhenti sampai di kelas saja, tetapi juga di luar kelas dengan memberikan kepada mereka, berupa tugas individu yakni hafalan mufradat yang sudah diberikan dan akan dihadapkan pada pertemuan kedua

Pada pertemuan selanjutnya yaitu pada tanggal 10 Oktober 2020 guru atau peneliti membuka pembelajaran dengan mengucapkan salam, membaca doa sebelum belajar secara bersama-sama. Dan yang terpenting guru tidak lupa untuk mengingatkan siswa agar selalu mengikuti protokol kesehatan karena penelitian ini dilaksanakan pada masa pandemi covid-19. Selanjutnya guru memulai pembelajaran dengan memberi motivasi berupa kata-kata bijak agar siswa lebih giat lagi belajar bahasa Arab. Dan meminta siswa untuk menghadapkan kosa katanya yang sudah dihafal, dengan pelafalan yang benar.

Pada pertemuan keempat yang dilaksanakan pada tanggal 17 Oktober 2020 guru membuka pembelajaran seperti pada pertemuan sebelumnya, dan tidak lupa mengingatkan siswa untuk selalu mengikuti protokol kesehatan yaitu dengan menjaga jarak. Proses yang dilakukaan hampir sama dengan pertemuan sebelumnya, yaitu memberi motivasi sebelum belajar dengan meminta salah satu siswa agar menceritakan kegiatannya ketika berada di sekolah sampai pulang kerumah dengan menggunakan bahasa Arab. prtemuan ini mengarah pada kemampuan berbicara maka guru dengan menuliskan dipapan tulis untuk memperlihatkan lebih jelas makhraj huruf dan makna dari tiap-tiap kosa kata yang ada dalam hiwar. hanya saja guru tidak terlalu menjelaskan tentang makna yaumiyyatuna fil madrasah dalam kehidupan sehari-hari. Akan tetapi sesekali guru mempertontonkan kepada siswa video yang berkaitan dengan materi ajar, yang lucu tetapi mengandung makna semangat kekeluargaan yang membuat mereka merindukan suasana sekolah, treatmen tersebut peneliti lakukan dalam pembelajaran agar siswa tidak hanya sekedar tahu tetapi 


\section{Loghat Arabi: Jurnal Bahasa Arab dan Pendidikan Bahasa Arab}

P-ISSN: 2722-1180 | E-ISSN: 2722-1199

Vol. 2, No. 1, Juni 2021

lebih faham terhadap apa yang mereka pelajari sehingga mereka termotivasi untuk melaksanakannya dalam kehidupan nyata.

Pertemuan selanjutnya dilakukan pada tanggal 24 Oktober 2020 dengan tetap menggunakan metode hiwar. Pada pertemuan ini guru menyuruh siswa untuk mempraktekkan semua materi hiwar yang telah diberikan kepada siswa, dengan cara siswa saling berhadapan dan melakukan hiwar. Setelah itu siswa maju kedepan siswa lain secara berpasangan untuk mempraktekkan hiwar. Cara ini dilakukan agar siswa selalu ingat tiap kalimat yang terdapat dalam hiwar dan menggunakannya dala kehidupan sehari-hari bersama teman-temannya.

Pada pertemuan terakhir atau keenam yang dilaksanakan pada tangga 31 Oktober 2020 guru memberikan soal- soal kepada siswa setelah penerapan metode hiwar dilaksanakan (postest). soal tersebut berupa test tulis. Test tulis ini bertujuan untuk mengetahui tingkat maharah kalam siswa kelas VIII setelah penerapan metode Hiwar dilaksanakan. Kegiatan ini dilaksanakan selama 1 jam. Yang dimulai dari jam 09.00-10.00.

Tingkat Maharah kalam siswa setelah penerapan metode hiwar, telah nengalami peningkatan dan telah mencapai kriteria ketuntasan minimum (KKM) yaitu nilai 68. Hal ini diketahui dari jumlah 20 siswa yang tuntas belajar sebanyak 18 anak atau siswa dan sisanya 2 anak atau $10 \%$ siswa belum tuntas. Sebagimana yang terdapat pada tabel berikut:

\begin{tabular}{|c|l|c|c|c|}
\hline No & Nama Siswa & Nilai & Tuntas & $\begin{array}{c}\text { Tidak } \\
\text { Tuntas }\end{array}$ \\
\hline 1. & S1 & 78 & $\sqrt{ }$ & \\
\hline 2. & S2 & 71 & $\sqrt{ }$ & \\
\hline 3. & S3 & 70 & $\sqrt{ }$ & \\
\hline 4. & S4 & 77 & $\sqrt{ }$ & \\
\hline 5. & S5 & 80 & $\sqrt{ }$ & \\
\hline 6. & S6 & 83 & $\sqrt{ }$ & \\
\hline 7. & S7 & 83 & $\sqrt{ }$ & \\
\hline 8. & S8 & 87 & $\sqrt{ }$ & \\
\hline 9. & S9 & 87 & $\sqrt{ }$ & \\
\hline 10. & S10 & 71 & $\sqrt{ }$ & \\
\hline 11. & S11 & 87 & $\sqrt{ }$ & \\
\hline 12. & S12 & 89 & $\sqrt{ }$ & \\
\hline 13. & S13 & 63 & & $\sqrt{ }$ \\
\hline 14. & S14 & 62 & & $\sqrt{ }$ \\
\hline 15. & S15 & 71 & $\sqrt{ }$ & \\
\hline 16. & S16 & 78 & $\sqrt{ }$ & \\
\hline
\end{tabular}




\section{Loghat Arabi: Jurnal Bahasa Arab dan Pendidikan Bahasa Arab}

\begin{tabular}{|l|l|l|l|l|}
\hline 17. & S17 & 74 & $\sqrt{ }$ & \\
\hline 18. & S18 & 79 & $\sqrt{ }$ & \\
\hline 19. & S19 & 88 & $\sqrt{ }$ & \\
\hline 20. & S20 & 79 & $\sqrt{ }$ & \\
\hline
\end{tabular}

Tabel 3. Hasil tes (post-test) setelah penerapan metode hiwar

Data di atas menunjukkan bahwa kemampuan siswa dalam melaksanakan keterampilah maharah kalam (bercakap Bahasa Arab) para siswa kelas VIII Hikmat Tuttula telah mencapai kriteria ketuntasan minimum (KKM). Data ini berdasar pada strandar kelulusan minimum pada mata pelajaran Bahasa arab yaitu nilai 68. Dan data hasil belajar Bahasa arab pada kemampuan maharah kalam siswa pada saat kami berikan posttest telah mencapai 18 orang siswa yang melulusi standar kelulusan minimum (KKM), dan dua orang (10\%) yang belum mencapai KKM.

\section{Efektifitas Penerapan Metode Hiwar Terhadap Peningkatan Maharah Kalam Siswa Kelas VIII Mts Himat Tuttula}

Setelah melihat hasil yang didapatkan baik sebelum maupun setelah penerapan metode hiwar, maka peneliti mengkaji tentang keefektifitasan metode hiwar terhadap peningkatan maharah kalam siswa dengan menggunakan perbandingan nilai dari pretes maupun posttest.

\begin{tabular}{|c|c|c|c|c|c|c|}
\hline \multirow{2}{*}{ No } & Interval & Kategori & \multicolumn{2}{c|}{ PRE TES } & \multicolumn{2}{c|}{ POST TES } \\
\cline { 4 - 7 } & Skor & Hasil Belajar & Frekuensi & Persentese & Frekuensi & Persentase \\
\hline 1 & $\leq 68$ & Tuntas & 7 & $35 \% \%$ & 18 & $90 \%$ \\
\hline 2 & $\geq 68$ & Tidak tuntas & 13 & $65 \% \%$ & 2 & $10 \%$ \\
\hline \multicolumn{2}{|c|}{ Jumlah } & 20 & $100 \%$ & 20 & $100 \%$ \\
\hline
\end{tabular}

Tabel 4. Hasil Distribusi Frekuensi dan Persentase Maharah Kalam

Pada tabel terlihat bahwa jumlah siswa yang lulus dalam ujian pretest sebanyak 7 orang dengan persentase $35 \%$ dan dalam ujian posttest sebanyak 18 orang dengan persentase $90 \%$. Selanjutnya, peneliti menyajikan presentase nilai rata-rata kenaikan hasil maharah kalam siswa kelas VIII MTs Hikmat Tuttula yang dilihat dari hasil pretest dan posttest untuk mengetahui tingkat kemampuan siswa sebagai berikut:

\begin{tabular}{|c|c|c|}
\hline \multirow{2}{*}{ Statistik } & \multicolumn{2}{|c|}{ Nilai Statistik } \\
\cline { 2 - 3 } & Pretest & Posttest \\
\hline Nilai rata-rata $(\mathrm{X})$ & 64.3 & 77.8 \\
\hline
\end{tabular}

Tabel 5. Nilai Rata-Rata Statistik Siswa Kelas VIII Mts Hikmat Tuttula 


\section{Loghat Arabi: Jurnal Bahasa Arab dan Pendidikan Bahasa Arab}

P-ISSN: 2722-1180 | E-ISSN: 2722-1199

Vol. 2, No. 1, Juni 2021

$$
\begin{array}{rl}
\mathrm{P}=\frac{Y-X}{X} x & 100 \% \\
& =\frac{77.8-64.3}{64.3} \times 100 \% \\
& =\frac{13.5}{64.3} \times 100 \% \\
& =20.99 \%
\end{array}
$$

Jadi, selisih rata-rata kenaikan hasil belajar siswa adalah 13.5 dengan persentase 20.99\%. Dari tabel dan perhitungan tersebut maka dapat disimpulkan bahwa metode hiwar efektif untuk meningkatkan maharah kalam siswa dengan persentase rata-rata kenaikan hasil belajar yaitu $20.99 \%$.

Berdasarkan hasil penelitian dengan menggunakan pre-eksperimental yang dilakukan terhadap 20 siswa mengenai tingkat maharah kalam siswa kelas VIII MTs Hikmat Tuttula sebelum dan sesudah perlakuan (treatment) penerapan metode hiwar, maka akan dianalisis juga dengan menggunakan analisis deskriptif untuk menggambarkan tingkat maharah kalam siswa kelas VIII sebelum (pretest) dan sesudah (posttest) diberi perlakuan (treatment), dan analisis uji test guna menguji hipotesis penelitian tentang adanya perbedaan tingkat maharah kalam siswa kelas VIII sebelum dan sesudah diberi perlakuan berupa penerapan metode hiwar.

\section{Hasil Uji Deskriptif}

Analisis statistik deskriptif dimaksudkan untuk memperoleh gambaran mengenai tingkat maharah kalam siswa kelas VIII sebelum (pre-test) dan sesudah (pot-test) diberi penerapan metode hiwar. Maka berikut disajikan data gambaran tentang mahrah kalam siswa kelas VIII sebelum (pre-test) dan sesudah (post-test) disajikan dalam bentuk tabel distibusi frekuensi dan persentase yang diklasifikasikan dalam 4 (empat) kategori yaitu, maharah kalam siswa tinggi, sedang, rendah, dan sangat rendah dengan hasil sebagai berikut:

\begin{tabular}{|c|c|c|c|c|}
\hline \multirow{2}{*}{ No. } & \multirow{2}{*}{ Interval } & \multirow{2}{*}{ kategori } & \multicolumn{2}{|c|}{ Pre-test } \\
\cline { 4 - 5 } & & & Frekuensi & Persentase \\
\hline 1. & $36-48$ & Tinggi & - & - \\
\hline 2. & $24-35$ & Sedang & 11 & $55 \%$ \\
\hline 3. & $12-23$ & Rendah & 6 & $30 \%$ \\
\hline 4. & $0-11$ & Sangat Rendah & 3 & $15 \%$ \\
\hline \multicolumn{3}{|c|}{ Jumlah } & 20 & $100 \%$ \\
\hline
\end{tabular}




\section{Loghat Arabi: Jurnal Bahasa Arab dan Pendidikan Bahasa Arab}

Tabel 6. Hasil Pre-test Angket Maharah Kalam Siswa Kelas VIII

Berdasarkan tabel diatas meunjukkan bahwa keterampilan maharah kalam siswa kelas VIII MTs Hikmat Tuttula sebelum penerapan metode hiwar, yaitu tidak ada siswa pada kategori tinggi, dan kategori sedang sebanyak 13 respondent (65\%), kemudian kategori rendah sebanyak 5 orang siswa (25\%), disusul kategori sangat rendah sebanyak 2 orang siswa (10\%). Selanjutnya dengan nilai rata-rata skor yang diperoleh sebanyak 20. Nilai rata-rata tersebut pada interval 12-23 yang berarti rendah. Hal ini berarti maharah kalam siswa kelas VIII MTs Himat Tuttula berada dalam kategori rendah.

Data hasil angket setelah diberikan penerapan metode hiwar disajiakan secara lengkap, yaitu sebagai berikut:

\begin{tabular}{|c|c|c|c|c|}
\hline \multirow{2}{*}{ No. } & \multirow{2}{*}{ Interval } & \multirow{2}{*}{ Kategori } & \multicolumn{2}{|c|}{ Pre-test } \\
\cline { 4 - 5 } & & & Frekuensi & Persentase \\
\hline 1. & $36-48$ & Tinggi & 13 & $65 \%$ \\
\hline 2. & $24-35$ & Sedang & 6 & $30 \%$ \\
\hline 3. & $12-23$ & Rendah & 1 & $5 \%$ \\
\hline 4. & $0-11$ & Sangat Rendah & - & - \\
\hline \multicolumn{3}{|c}{ Jumlah } & 20 & $100 \%$ \\
\hline
\end{tabular}

Tabel 7. Hasil Post-test Angket Maharah kalam Siswa kelas VIII

Setelah peneliti melaksanasakan penerapan metode hiwar kepada siswa kelas VIII MTs Hikmat Tuttula, maharah kalam siswa kelas VIII mengalami peningkatan. Hal ini dapat dilihat pada tabel diatas bahwa Maharah kalam siswa kelas VIII mengalami peningkatan ketika peneliti melaksanakan penerapan metode hiwar yaitu terdapat 13 siswa (65\%) pada kategori tinggi, kemudian kategri sedang sebanyak 6 siswa (30\%), dan kategori rendah sebanyak 1 siswa $(5 \%)$. Tidak ada siswa yang terdapat pada kategori sangat rendah.

Selanjutnya dengan nilai rata-rata skor yang diperoleh sebesar 38. Nilai rata-rata pada tersebut interval 36-48 yang berarti tinggi. Penelitian ini hanya dilaksanakan sebanyak 6 kali petemuan, karena penelitian ini dilaksanakan selama pandemi.

2. Hasil Observasi

Hasil observasi selama pemberian penerapan metode hiwar dilakasanakan sebanyak enam kali pertemuan diperoleh data sebagai berikut: 


\section{Loghat Arabi: Jurnal Bahasa Arab dan Pendidikan Bahasa Arab}

\begin{tabular}{|c|c|c|c|c|c|c|c|}
\hline \multirow{2}{*}{ Persentase } & \multirow{2}{*}{ Kriteria } & \multicolumn{7}{|c|}{ Pertemuan } \\
\cline { 3 - 8 } & & I & II & III & IV & V & VI \\
\hline $80 \%-100 \%$ & Sangat Tinggi & - & - & 1 & 3 & 4 & 6 \\
\hline $60 \%-79 \%$ & Tinggi & 2 & 2 & 5 & 7 & 7 & 7 \\
\hline $40 \%-59 \%$ & Sedang & 4 & 6 & 6 & 6 & 6 & 6 \\
\hline $20 \%-39 \%$ & Rendah & 14 & 12 & 8 & 4 & 3 & 1 \\
\hline $0 \%-19 \%$ & Sangat Rendah & - & - & - & - & - & - \\
\hline \multicolumn{2}{|c|}{ Jumlah } & $\mathbf{2 0}$ & $\mathbf{2 0}$ & $\mathbf{2 0}$ & $\mathbf{2 0}$ & $\mathbf{2 0}$ & $\mathbf{2 0}$ \\
\hline
\end{tabular}

Tabel 8. Data Hasil Persentase Observasi Pelaksanaan Metode Hiwar

Berdasarkan hail observasi yang dilaksanakan pada pertemuan pertama, tidak ada siswa yang terdapat pada kategori sangat rendah dan sangat tinggi, kemudian kategori rendah tedapat 14 siswa, pada kategori sedang terdapat 4 orang siswa dan pada kategori tinggi terdapat 2 siswa. Pada pertemuan kedua masih belum ada siswa yang terdapat pada kategori sedang, pada kategori masih terdapat 2 orang siswa, kemudiam kategori sedang sudah mulai ada peningkatan karena terdapat 6 siswa, pada kategori rendah terdapat 12 siswa dan tidak ada siswa yang terdapat pada kategori sangat rendah. Di pertemuan ketiga sudah mulai ada peningkatan, karena pada kategori sangat terdapat 1 siswa, pada kategori tinggi terdapat 5 anak, kategori sedang terdapat 6 siswa, pada kategri rendah terdapat 8 siswa, dan tidak ada siswa yang terdapat pada kategori sangat rendah. Pada pertemuan keempat sudah ada 3 orang siswa yang terdapat pada kategori sangat tinggi, kemudian pada kategori inggi terapat 7 siswa, pada kategori sedang terdapat 6 siswa, pada kateori rendah terdapat 4 siswa, dan tidak ada siswa yang terdapat pada kategori sangat rendah. Pada pertemuan kelima, terdapat 4 siswa pada kategori sangat tinggi, disusul kategori tinggi yang terdapat 7 orang siswa, pada kategori sedang terdapat 6 siswa, pada kategori rendah terdapat 3 siswa, dan tidak ada siswa yang terdapat pada kategori sangat rendah. Pada pertemuan terakhir atau keenam, pada kategori tedapat sangat tinggi tardapat 6 siswa, pada kategori tinggi terdapat 7 siswa, pada kategori sedang terdapat 6 siswa, pada kategori rendah terdapat 1 orang siswa, an tidak ada siswa yang terdapat pada kategori sangat rendah. 


\section{Loghat Arabi: Jurnal Bahasa Arab dan Pendidikan Bahasa Arab}

Berdasarkan hasil yang diperoleh menunjukkan bahwa siswa mengalami peningkatan atau kemajuan dalam hal keaktifan pada saat pelaksanaan metode Hiwar. Hal ini menandakan bahwa siswa antusias dalam mengikuti penerapan metode hiwar dalam pembelajaran bahasa Arab.

\section{Simpulan}

Tingkat maharah kalam siswa kelas VIII sebelum perlakuan (treatment) penerapan metode hiwar diberikan yaitu Tingkat maharah kalam siswa sebelum penerapan metode hiwar, dikatakan masih rendah dan belum mencapai kriteria ketuntasan minimum (KKM) yaitu nilai 68. Hal ini diketahui dari jumlah 20 siswa yang tuntas belajar baru 7 anak atau 35\% siswa dan sisanya sisanya 13 anak atau 65\% siswa belum tuntas. Kemudian Setelah peneliti melaksanasakan penerapan metode hiwar. kemampuan siswa dalam melaksanakan maharah kalam (keterampilan berbicara) para siswa kelas VIII Hikmat Tuttula masih sangat kurang. Data ini berdasar pada strandar kelulusan minimum pada mata pelajaran Bahasa arab yaitu nilai 68 sedangkan data hasil belajar Bahasa arab pada kemampuan maharah kalam siswa pada saat kami berikan pretest hanya 7 orang saja yang melulusi standar kelulusan minimum. Penerapan metode hiwar terhadap tingkat maharah kalam siswa kelas VIII MTs Himat Tuttula. Setelah melihat hasil yang didapatkan baik sebelum maupun setelah penerapan metode hiwar, dengan selisih ratarata kenaikan hasil maharah kalam siswa antara pretest dan posttest adalah 13,5 dengan persentase 20,99\%. Maka metode hiwar efektif dalam peningkatan maharah kalam siswa.

\section{Daftar Pustaka}

Aliyan, Ahmad Fuad Mahmud. al-Maharat al-Lughawiyyah: Mahiyatuha wa TharaiqTadrisiha. Riyadh: Dar al-Muslim lin Nasyr wat Tauzi', 1992.

Imam Kurniawan, Anung Al Hamat, and Abdul Hayyi Al Kattani. "Metode Pembelajaran Kreatif Mata Pelajaran Bahasa Arab Untuk Kelas 1 Sekolah Dasar Islam." Idarah Tarbawiyah: Journal of Management in Islamic Education 2.1 (2021): 13-20. https://doi.org/10.32832/itjmie.v2i1.3426

M. Abdul Hamid, dkk., Pembelajaran Bahasa Arab: Pendekatan, Metode, Startegi, Materi dan Media. Cet. I; Malang: UIN-Malang Press, 2008. 


\section{Loghat Arabi: Jurnal Bahasa Arab dan Pendidikan Bahasa Arab}

P-ISSN: 2722-1180 | E-ISSN: 2722-1199

Vol. 2, No. 1, Juni 2021

Mahmud, Basri, and Hamzah Hamzah. "Pembelajaran Efektif dalam Pengajaran Bahasa Arab Tingkat Menengah." Loghat Arabi: Jurnal Bahasa Arab dan Pendidikan Bahasa Arab 1.1 (2020): 23-36. https://journal.iaiddipolman.ac.id/index.php/loghat/article/view/3

Muhammad Zakir. "Metode Mengajar dalam Pendidikan Islam (Kjian Tafsir Tarbawi)." Serambi tarbawi 4.2 (2016): 101-118. https://doi.org/10.32672/tarbawi.v4i2.1267

Pambudi, Khafid. Pengaruh Pelaksanaan Praktek Muhadhasah Pagi terhadap Prestasi Belajar PAI (Materi al-Qur'an Hadits) Siswa di SMP Plus ar-Rahmat Bojonegoro. Diss. UIN Sunan Ampel Surabaya, 2014. http://digilib.uinsby.ac.id/820/

Peraturan Pemerintah RI Nomor 19 tahun 2005 tentang Standar Nasional Pendidikan

Syarabiy, Mahmud 'Ali. Dalil Muta'allimiy al-'Arabiyyah lin Nathiqiyna bi Ghayriha. Riyadh: Dar Wojooh lin Nasyir wat Tauzi’, 2015.

Syarabiy, Mahmud Ali Muhammad. Istratiyjiyyah Muqtarahah Qaimah 'ala Madkhal alTaqabuli al-Lughawiy wa Thalil al-Akhtha' fi Tanmiyah Maharat al-Fahmi al-Istima'iy wal Qira'ah al-jahriyyah wal Kitabah al-Wadhzifiyah laday Darisiy al-Lughah al'Arabiyyah al-Natiqinan bi Ghairiha, Risalah Dukturah. Ma'had al-Dirasat alTarbawiyyah, Jami'ah al-Qahirah, 2011. 


\section{Loghat Arabi: Jurnal Bahasa Arab dan Pendidikan Bahasa Arab}

